Article

\title{
An Intelligent Lightning Warning System Based on Electromagnetic Field and Neural Network
}

\author{
Guoming Wang $\left.{ }^{1} \mathbb{(}\right)$, Woo-Hyun Kim ${ }^{1}$, Gyung-Suk Kil ${ }^{1, *} \mathbb{(}$, Dae-Won Park ${ }^{2} \mathbb{C}$ \\ and Sung-Wook Kim ${ }^{3}$ \\ 1 Department of Electrical and Electronics Engineering, Korea Maritime and Ocean University, Busan 49112, \\ Korea; journey@kmou.ac.kr (G.W.); steady92@kmou.ac.kr (W.-H.K.) \\ 2 R\&D Center, EMI Solutions Co., LTD., Busan 49112, Korea; stradlin77@naver.com \\ 3 Power Asset Management Team, R\&D Center, Hyosung Corporation, Changwon 51529, Korea; \\ number1@hyosung.com \\ * Correspondence: kilgs@kmou.ac.kr; Tel.: +82-51-410-4414
}

Received: 28 February 2019; Accepted: 26 March 2019; Published: 2 April 2019

check for updates

\begin{abstract}
Prediction of lightning occurrence has significant relevance for reducing potential damage to electric installations, buildings, and humans. However, the existing lightning warning system (LWS) operates using the threshold method and has low prediction accuracy. In this paper, an intelligent LWS based on an electromagnetic field and the artificial neural network was developed for improving lightning prediction accuracy. An electric field mill sensor and a pair of loop antennas were designed to detect the real-time electric field and the magnetic field induced by lightning, respectively. The change rate of electric field, temperature, and humidity acquired 2 min before lightning strikes, were used for developing the neural network using the back propagation algorithm. After observing and predicting lightning strikes over six months, it was verified that the proposed LWS had a prediction accuracy of $93.9 \%$.
\end{abstract}

Keywords: lightning warning system; electric field mill; loop antenna; artificial neural network; prediction accuracy

\section{Introduction}

Lightning is a common natural phenomenon mainly occurring within cloud-to-ground and cloud-to-cloud which, however, causes damages to electrical installations, buildings, and humans due to its large current as well as induced transient voltage [1-3]. Recently, affected by climate change and global warming, lightning has occurred more frequently compared to previous years. It was reported by the National Aeronautics and Space Administration that the incidence of lightning increases approximately $5 \%-6 \%$ when the global surface temperature increases by $1{ }^{\circ} \mathrm{C}[4,5]$. Figure 1 a shows the number of lightning occurrences from 2008 to 2017 in South Korea. The lightning incidence increased significantly from 2014 to 2017, and occurred 316,679 times in total in 2017. From Figure 1b, which shows number of lightning every month in 2017, it can be seen that lightning occurred more frequently from May to August due to the high temperature [6].

Although lightning rod, arrester, and surge protective devices are implemented to project objects against lightning, there are still areas such as outdoor farmland, golf courses, mountains, and etc. out of protection areas. To reduce the risk of being damaged by lightning, especially to avoid humans being injured, a lightning warning system (LWS) is necessary to predict and to alert the potential lightning strike. In addition, the data acquired from LWS can be used for long-term meteorological evaluation, including the analysis of thunderstorm days, lightning density distribution map, and climate change. The LWS operates based on the detection of electric field between clouds and ground, and various 
sensors such as electric field mill (EFM), flat-plate antenna, whip antenna, and electro-optic sensor have been developed. Among the different detection sensors, the EFM sensor is the most widely used owing to its advantages of high detection sensitivity and high corrosion protection ability. However, previous works focused on the development of hardware system and the existing LWS predicts occurrence of lightning strike only based on the magnitude of electric field [7-10]. From the field experience and previous published works, these fields are influenced by the temperature and humidity, lowering the prediction accuracy of a lightning strike [11-13]. Therefore, it is necessary to develop an intelligent lightning prediction algorithm that takes the ambient temperature and humidity into consideration.

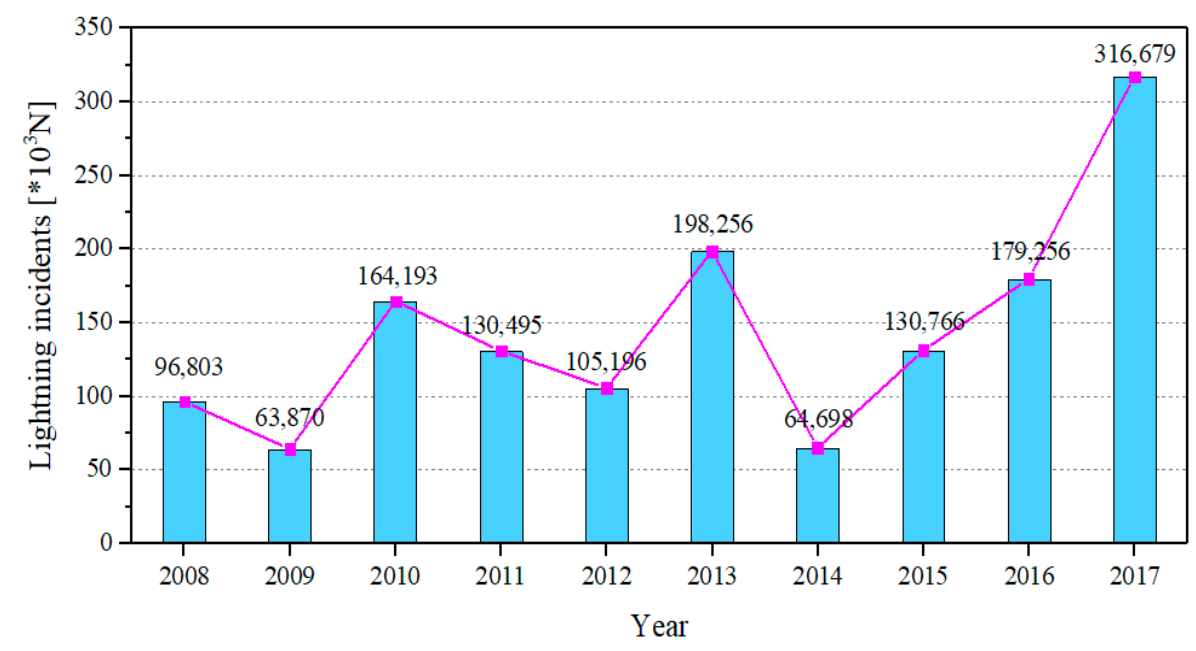

(a)

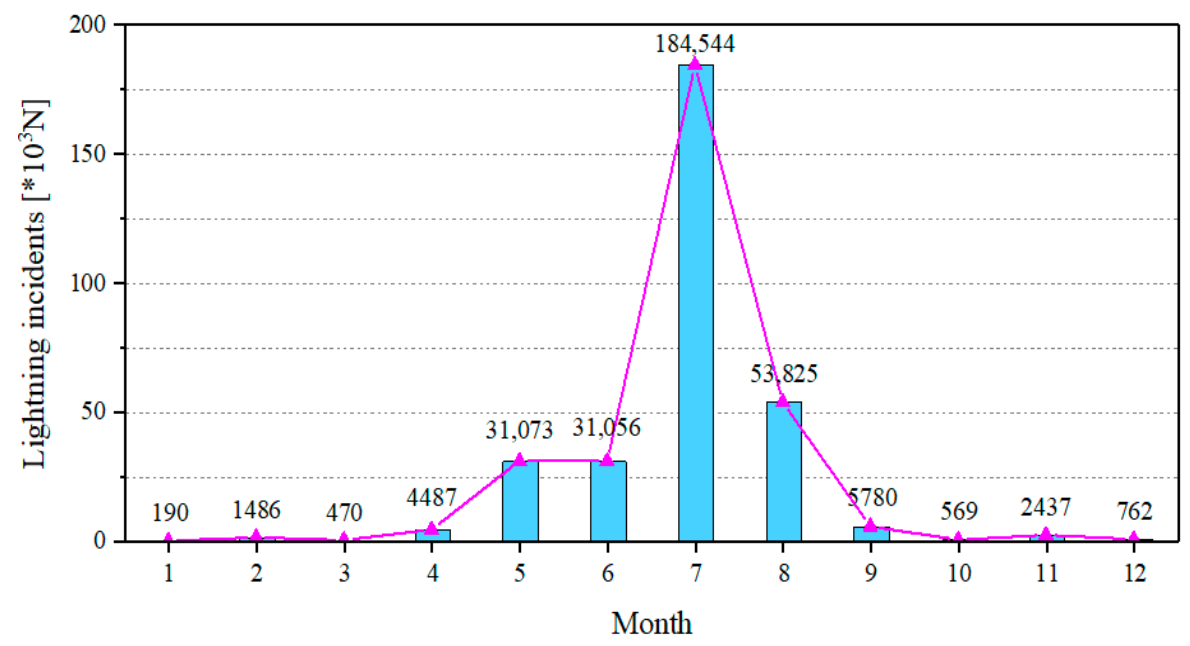

(b)

Figure 1. Lightning incidents in South Korea. (a) Number of lightning strikes in 2008-2017; (b) number of lightning strikes every month in 2017.

In this paper, a LWS that was mainly composed of an EFM sensor to measure the atmospheric electric field and a pair of loop antennas to estimate the lightning location was designed. Furthermore, an intelligent lightning prediction algorithm based on artificial neural network (ANN), which took the change rate of electric field, temperature, and humidity factors into consideration, was developed to improve the prediction accuracy. From the results, the lightning prediction accuracy of the proposed system was improved to $93.9 \%$, which was $27.1 \%$ higher than the existing method that only considers the magnitude of the electric field. 


\section{Detection of Electric and Magnetic Field}

\subsection{Electric Field Mill (EFM) Sensor}

The EFM sensor was used to detect the atmospheric electric field between cloud and ground and to provide an advanced warning before a lightning incident occurs $[7,14]$. The configuration of the fabricated EFM sensor is shown in Figure 2. It was mainly composed of a sensing plate and a rotating plate that was grounded. Both plates were designed with 6 vanes and were made of aluminum, which were lightweight and anticorrosive. The rotating plate was driven by a brushless direct current (BLDC) motor with a constant speed and, therefore, the sensing plate was exposed and shielded from the electric field periodically, resulting in the charge and discharge of the sensing plate.

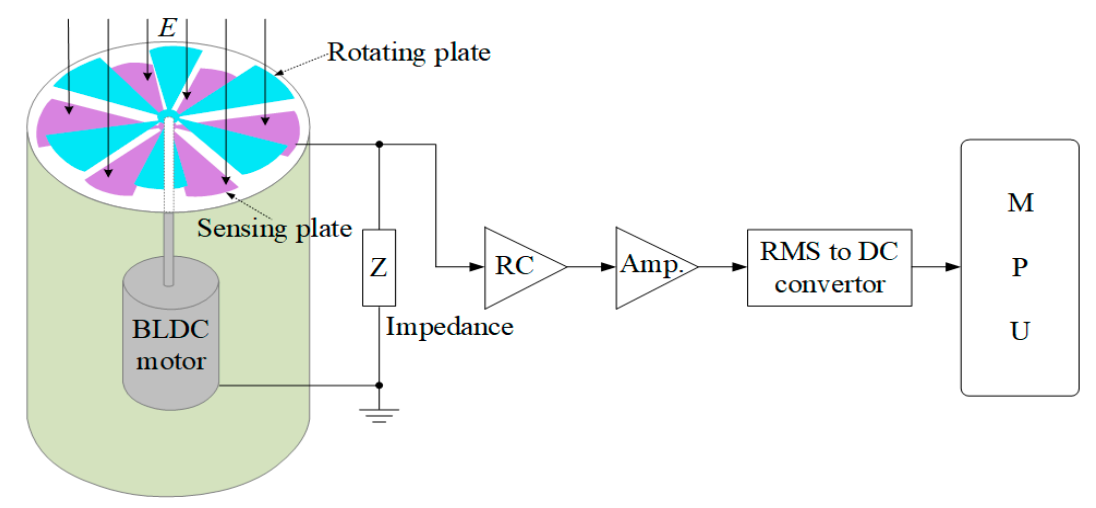

(a)

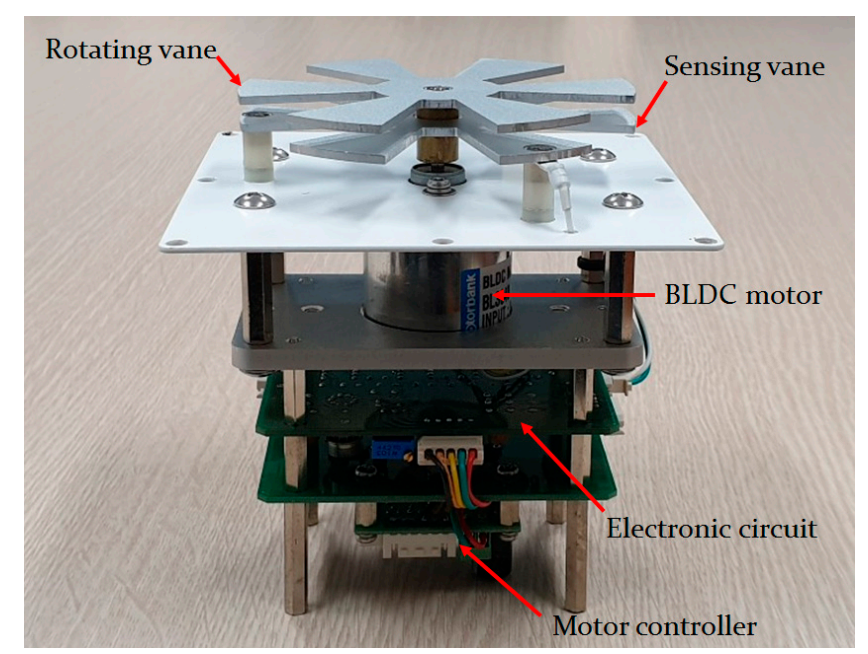

(b)

Figure 2. Electric field mill (EFM) sensor. (a) Configuration; (b) photograph.

When the sensing plate is shielded by the rotating plate, the accumulated charges transfer from the impedance to ground. The charges induced from the electrostatic field are given by:

$$
q=\int \bar{D} d A=\varepsilon_{0} E A
$$

where $\bar{D}$ is the electric flux intensity, $A$ is the area of sensor plate, $\varepsilon_{0}$ is the permittivity of vacuum, and $E$ is the electric field. As the motor rotates, the exposed area $a$ of sensing plate changes as:

$$
a=\frac{A(1+\sin \omega t)}{2}
$$


where $\omega$ is the angular velocity. Therefore, the accumulated charges on the sensor plate can be expressed by:

$$
q=\frac{\varepsilon_{0} E A(1+\sin \omega t)}{2}
$$

The voltage across the impedance can be calculated by:

$$
v(t)=Z_{i} \frac{d q}{d t}=\frac{\varepsilon_{0} E A \omega}{2} Z_{i} \cos \omega t
$$

The impedance consists of a resistor and a capacitor. The value of voltage $v(t)$ depends on the resistance $R$, the capacitance $C$, and angular velocity, which can be given by:

$$
v(t)= \begin{cases}\frac{\varepsilon_{0} E A \omega R}{2} & (\omega R C)^{2} \ll 1 \\ \frac{\varepsilon_{0} E A}{2} & (\omega R C)^{2} \gg 1\end{cases}
$$

In Equation (5b), the output voltage is proportional to the electric field and, therefore, is used in this paper. The output impedance consisted of a resistor of $100 \mathrm{M} \Omega$ and a capacitor of $100 \mathrm{nF}$. The rotate speed of motor was $2000 \mathrm{rpm}$. A motor controller was set to detect the rotational speed of motor. As the electric field changed instantly with time, an integrating circuit was used to compensate the original value. To improve the measuring sensitivity, a two-stage amplifier with a gain of $40 \mathrm{~dB}$ was designed. In addition, a root-mean-square (RMS) to DC converter was used for converting the magnitude of electric field to the input of microprocessor unit (MPU).

A calibration experiment was conducted to verify the linearity between the input electric field and the output voltage of EFM. As shown in Figure 3a, a high voltage direct current (HVDC) generator with a maximum output of $\pm 10 \mathrm{kV}$ was used to generate electric field between two copper plates. The diameter of the plates was $1000 \mathrm{~mm}$ and the distance between the two plates was $100 \mathrm{~mm}$. The edges of the plates were rounded to avoid the distortion of electric field owing to concentration. The EFM was placed at the center of the higher plate to detect the electric field intensity. The output voltages of EFM were recorded by a digital storage oscilloscope (DSO). Figure 3b shows the input high voltage and output signal of EFM sensor. The input electric field and the output of the EFM sensor were $80 \mathrm{kV} / \mathrm{m}$ and $3.9 \mathrm{~V}$, respectively. The calibration result is shown in Figure 3c. It can be seen that the designed EFM sensor had a linear response to the input electric field up to $80 \mathrm{kV} / \mathrm{m}$ and the detection sensitivity was $48.75 \mathrm{mV} / \mathrm{kV} / \mathrm{m}$.

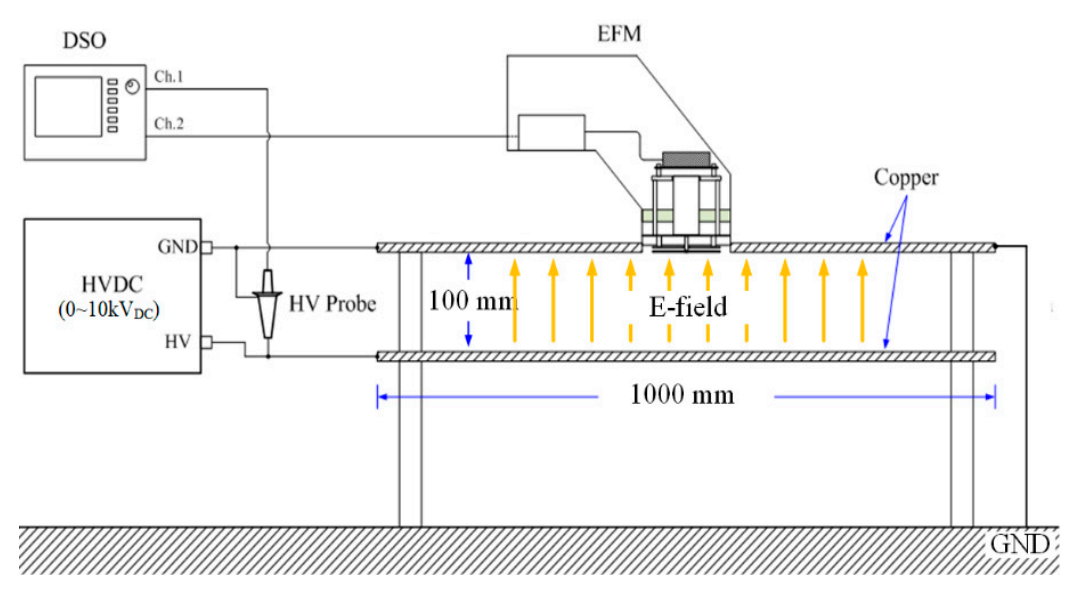

(a)

Figure 3. Cont. 


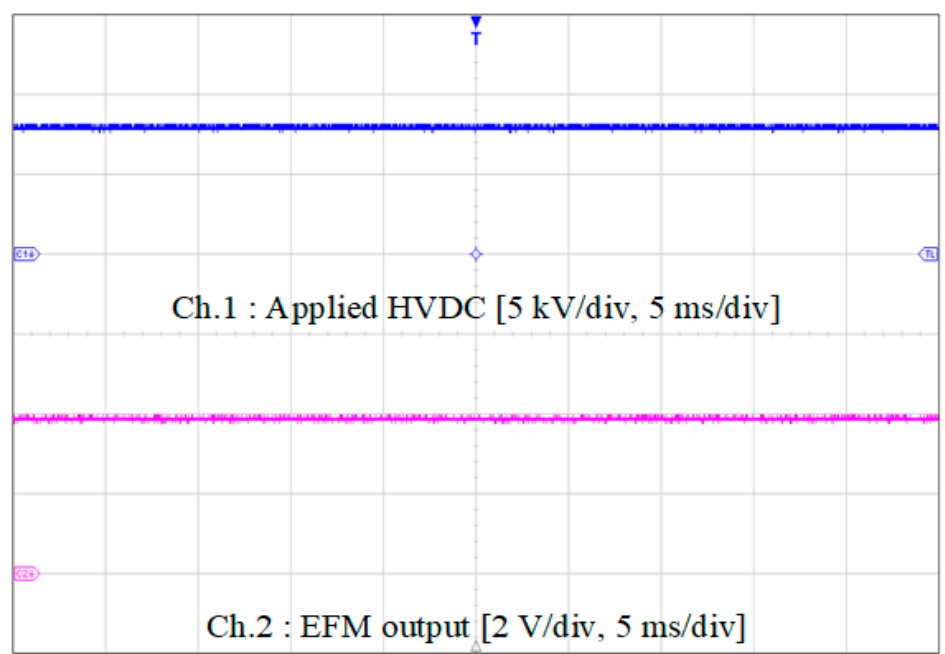

(b)

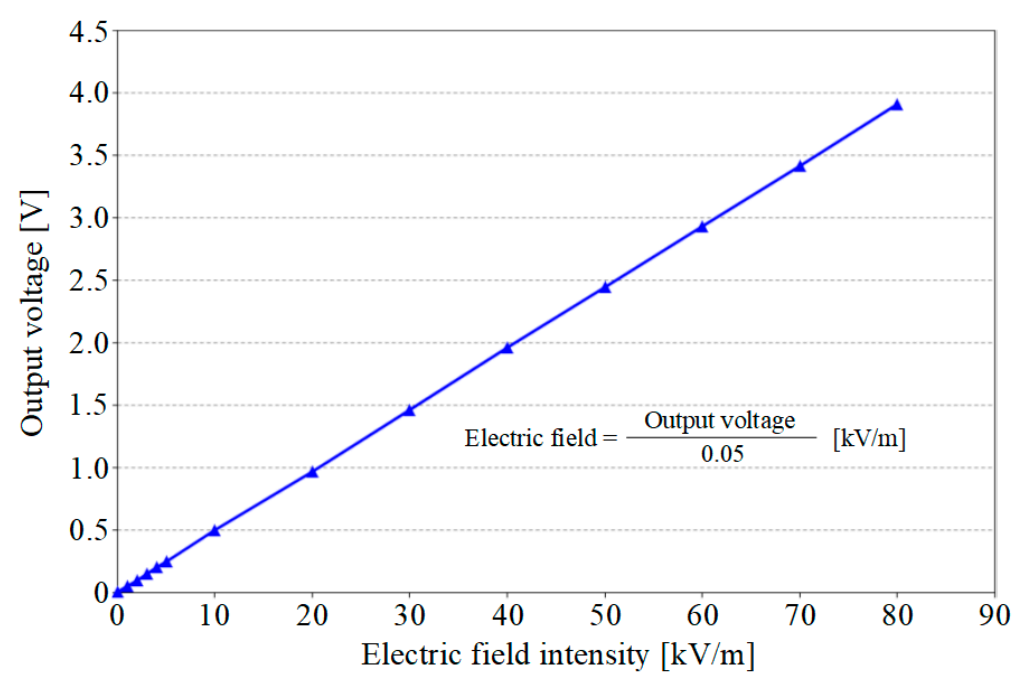

(c)

Figure 3. Calibration of EFM sensor. (a) Experimental setup; (b) output signals; (c) result.

\subsection{Loop Antenna}

A vertical and an orthogonal loop antenna were used to detect the induced magnetic field in order to estimate the location of a lightning strike $[8,10]$. The loop antenna worked based on the principle of Maxwell's Equation:

$$
\int_{L} E \cdot d L=-\int_{A} \frac{\partial B}{\partial t} \cdot d A=-\frac{d \Phi}{d t}
$$

where $E$ is the electric field that the magnetic flux $\Phi$ causes, $B$ is the magnetic flux density, and $d L$ and $d A$ are the differential length and area vector, respectively. The voltage $V$ induced at the loop antenna can be written as:

$$
V=-\frac{d \Phi}{d t}=-A \cdot \frac{d B}{d t}
$$

The equivalent circuit of loop antenna is shown in Figure 4. $L$ is the inductance of coil and $R$ is the input resistance of detection circuit. According to Kirchhoff's law, the following Equation can be obtained:

$$
V=-\mathrm{A} \cdot \frac{d B}{d t}=L \frac{d I}{d t}+R I
$$




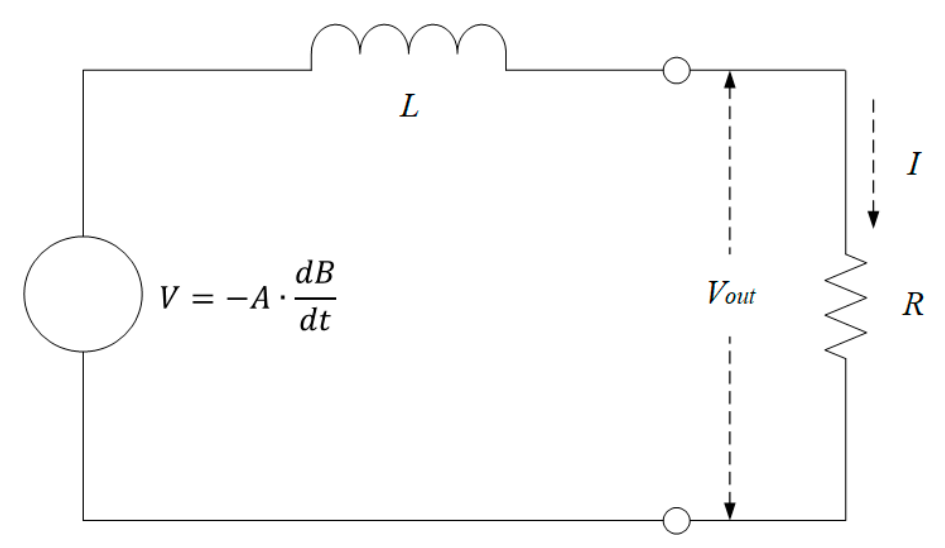

Figure 4. Equivalent circuit of loop antenna.

In case $R I \gg L \frac{d I}{d t}$, the current flowing through the detection resistor can be described as:

$$
I=-\frac{A}{R} \cdot \frac{d B}{d t}
$$

The direction of lightning was estimated by a pair of north-south (NS) and east-west (EW) oriented loop antenna, which were perpendicularly placed. As shown in Figure 5a, the ratio of two voltages induced from loop antennas is proportional to the angle $\theta$ that can be determined as:

$$
\theta=\tan ^{-1}\left(\frac{V_{\text {out }, N S}}{V_{\text {out }, E W}}\right)
$$

where $V_{\text {out,NS }}$ and $V_{\text {out }, E W}$ are the output voltages of NS loop and EW loop, respectively. Figure 5b shows the photograph of loop antennas and its detection circuits, which were mainly composed of an integrating circuit, an amplifier, and a peak detection circuit. The compact configuration avoided the distortion of the magnetic signal and reduced external interference significantly, which can improve the detection accuracy.

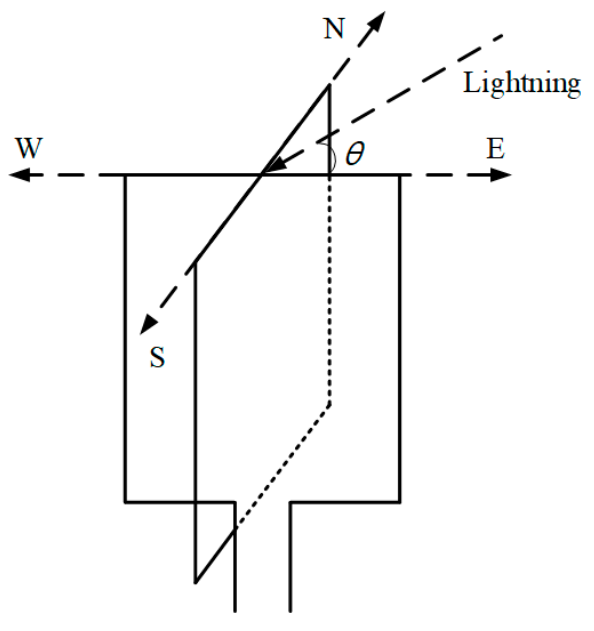

(a)

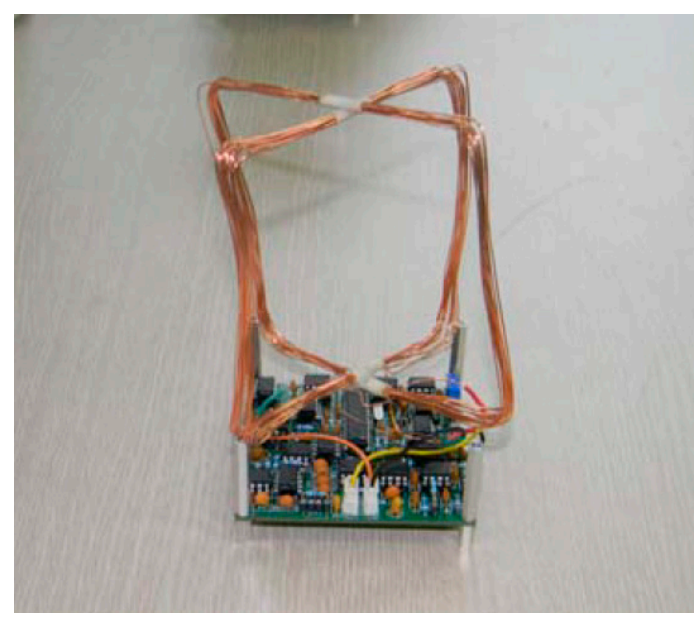

(b)

Figure 5. Loop antennas. (a) Schematic; (b) photograph and detection circuit.

To verify the response of the designed loop antennas, it was used to detect an $8 / 20 \mu \mathrm{s}, 500 \mathrm{~A}$ lightning impulse generated by a surge generator. Examples of waveforms of output voltages are shown in Figure 6. Since the NS loop and EW loop received almost the same amount of magnetic flux when the antenna was placed in the north-east direction, output voltages in Figure 6a had a similar 
magnitude. On the other hand, the NS loop received more magnetic flux than the EW loop when the antenna was placed in north-south direction, output voltage of NS loop in Figure $6 \mathrm{~b}$ was higher.

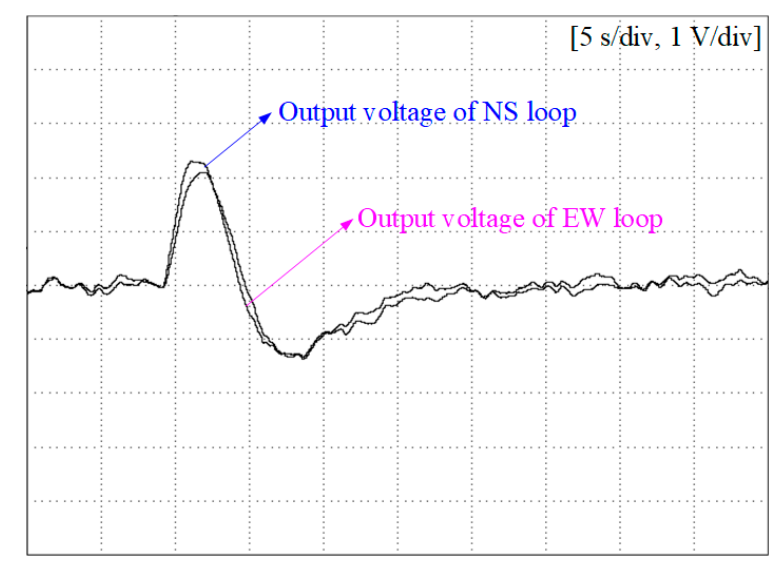

(a)

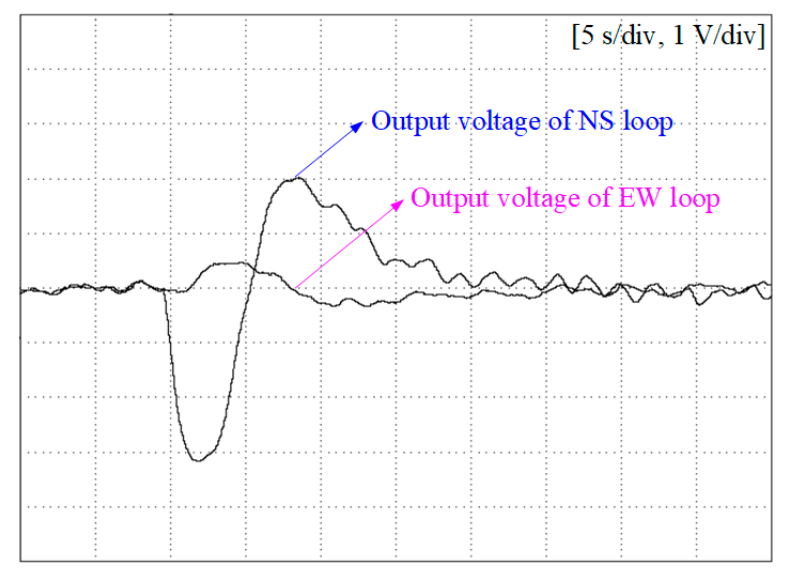

(b)

Figure 6. Examples of output voltages of loop antennas. (a) Response of antennas placed in north-east direction to positive lightning; (b) response of antennas placed in north-south direction to negative lightning.

The lightning distance $D$ can be estimated using the time-varying magnetic field associated with lightning $[15,16]$. When the charges within a thundercloud are assigned to be an electric dipole moment, the magnetic field on the ground at distance $D$ can be given by:

$$
B=\frac{\mu_{0}}{4 \pi D^{2}} \cdot\left[\frac{d M}{d t}\right]+\frac{\mu_{0}}{4 \pi c D} \cdot\left[\frac{d^{2} M}{d t^{2}}\right]
$$

where $\mu_{0}$ is the permeability of vacuum, $M$ is the sum of electric dipole moments of charges and their images, $c$ is the velocity of light. The first part on the right-hand side is called the magneto static term and the last part is radiation term, which represents energy propagated away from the lightning source at the speed of light and is proportional to the time rate. The distance can be estimated by the zero-crossing time on the magnetic field waveform.

\section{Intelligent Lightning Warning}

\subsection{Data Acquisition}

The existing LWS predicts lightning strikes by setting thresholds of electric field after analyzing a large number of observed lightning strike and electric field data. For instance, in case the detected value is between $20 \mathrm{kV} / \mathrm{m}$ and $50 \mathrm{kV} / \mathrm{m}$, only a warning signal is presented to indicate an increase in electric field. When the electric field is higher than $50 \mathrm{kV} / \mathrm{m}$, an alert signal is used to indicate the potential occurrence of lightning strikes. However, field results reveal that the threshold method has low prediction accuracy. To be specific, lightning may occur when the electric field is between $20 \mathrm{kV} / \mathrm{m}$ and $50 \mathrm{kV} / \mathrm{m}$ and may not occur even if the electric field is over $50 \mathrm{kV} / \mathrm{m}$. Possible atmospheric factors that affect the prediction accuracy are temperature and humidity. Therefore, the temperature and humidity were used along with the electric field for predicting the lightning occurrence.

Figure 7 shows data acquisition of electric field, temperature, humidity, and occurrence of a lightning strike. In case 1, one lightning strike was observed at the time of 20:22:26. At that time, the electric field was measured as $40.05 \mathrm{kV} / \mathrm{m}$, which was lower than the threshold of lightning alert for the existing LWS. In case 2, 17 lightning strikes were observed between 12:36:57 and 13:08:47. In this period, occurrence of lightning strikes also cannot be accurately predicted only by the electric field. 
Therefore, the change rate of the electric field within $5 \mathrm{~s}$, temperature, and humidity 2 min before lightning strikes were abundantly collected for developing the intelligent LWS based on ANN.

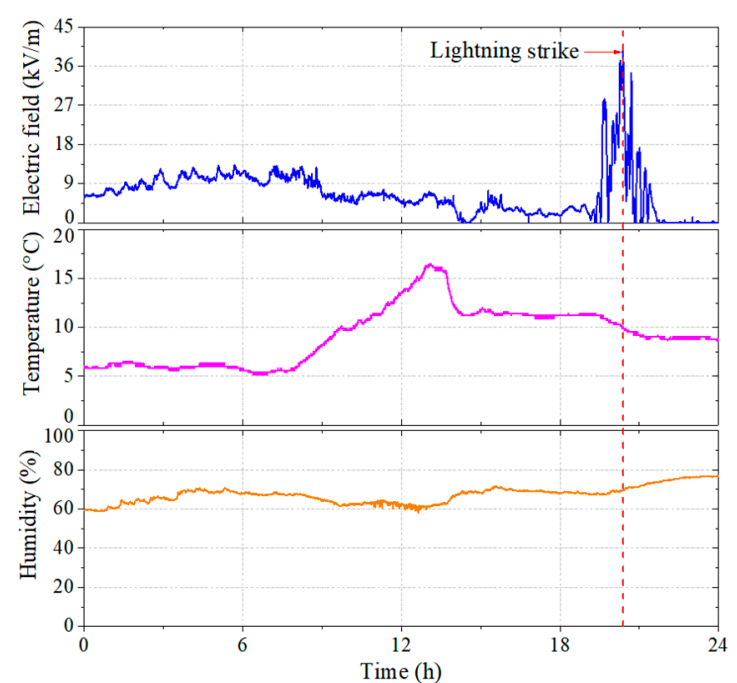

(a)

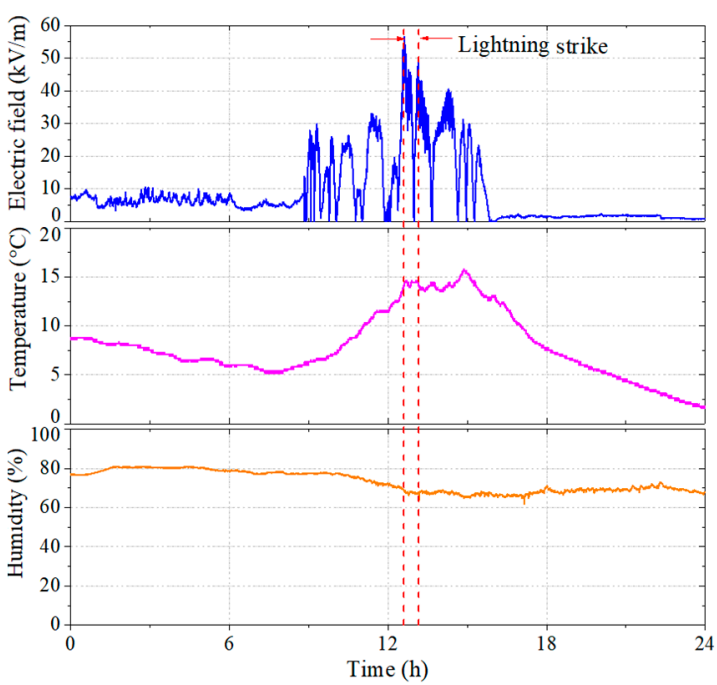

(b)

Figure 7. Electric field, temperature, humidity, and lightning data acquisition. (a) Case 1; (b) Case 2.

\subsection{Artificial Neural Network (ANN)}

The structure of the neural network is shown in Figure 8. There were three neurons in the input layer, whose values were change rate of electric field, temperature, and humidity. The output layer was the result of lightning prediction. Two hidden layers were used to connect the neurons in the input and output layer. The neurons in different layers were connected by weights, biases, and activation function. The weights and biases were randomly initialized to a small value from -0.2 to 0.2 . In addition, a sigmoid function was selected to determine the activation function. The back propagation algorithm was used to train the weights between neurons in each layer by using the 2000 sets of collected electric field, temperature, and humidity. This was made from the forward propagation of input data and back propagation of error. In the forward propagation, input parameters transferred from input layer to output layer without change of weights and biases. By contrast, in the back propagation, errors calculated by comparing actual output and desired output propagate from output layer to input layer with update of weights and biases. The back propagation algorithm continuously operated until the allowable error was less than 0.0001 and then the trained weights were updated in the system for real-time lightning warning [17-19]. This intelligent algorithm was developed based on the LabVIEW program with the standard state machine design pattern.

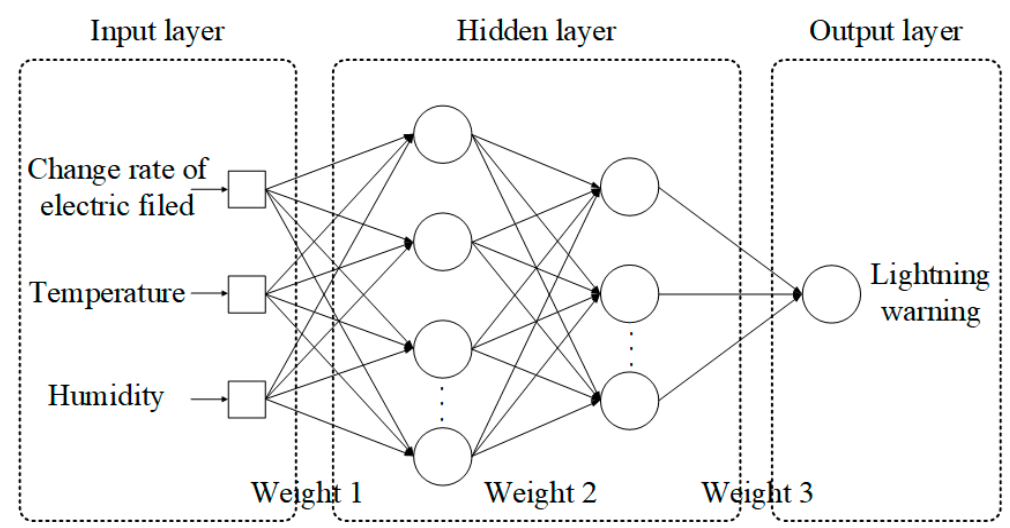

Figure 8. Structure of artificial neural network. 
The front panel and installation of the LWS are demonstrated in Figure 9. To evaluate the performance of the proposed LWS, it was used to predict lightning occurrences in six months and the results were compared with these acquired by the loop antennas. Ten data groups of comparison of lightning prediction accuracy between existing and proposed method are shown in Table 1. It can be seen that the existing method failed to predict lightning strike in the data group of 2,3,6, and 8 . In the data group of 2,6, and 8, lightning strikes occurred even though the electric filed was below $50 \mathrm{kV} / \mathrm{m}$. In data group 3, a lightning strike did not occur but was incorrectly predicted by the threshold method. However, the proposed method based on the change rate of electric field, temperature, and humidity accurately predicted the 10 cases. During six months, it was verified that 3674 lightning incidents were recorded by the loop antennas; 3449 of them were successfully predicted by the proposed system; whereas only 2453 lightning incidents were accurately predicted by the LWS based on the threshold method.

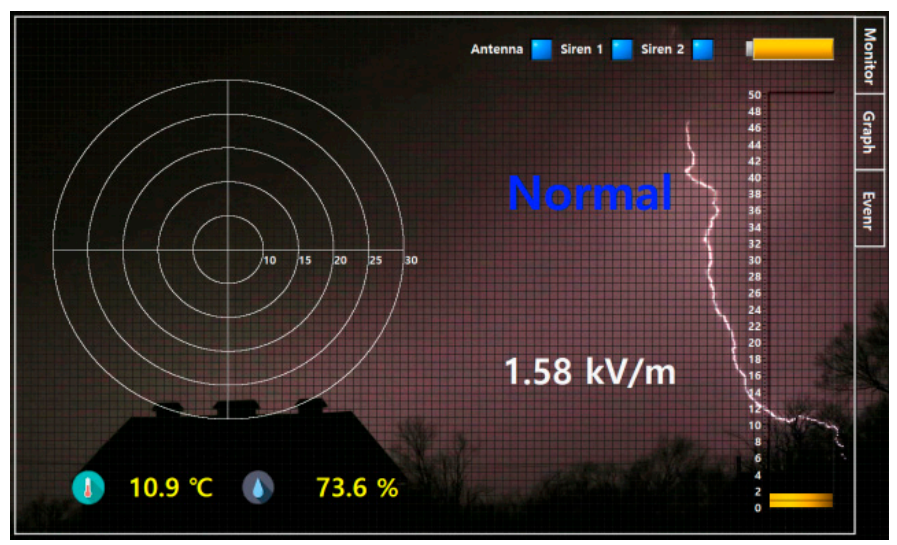

(a)

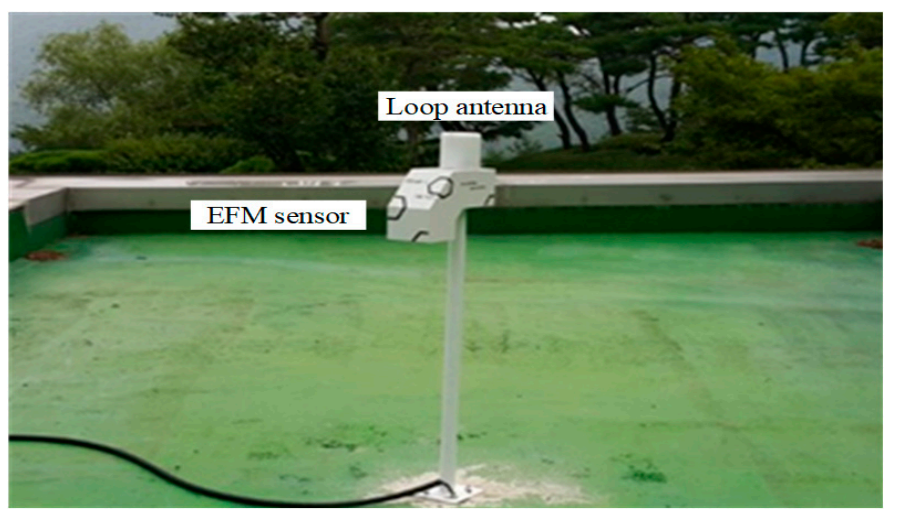

(b)

Figure 9. Lightning warning system. (a) Front panel; (b) installation. 
Table 1. Example of comparison of lightning prediction accuracy between existing and proposed method.

\begin{tabular}{ccccccc}
\hline \multicolumn{2}{c}{ Existing Method } & \multicolumn{5}{c}{ Proposed Method } \\
\cline { 2 - 7 } & $\begin{array}{c}\text { Electric Field } \\
\mathbf{( k V / m )}\end{array}$ & $\begin{array}{c}\text { Accurately } \\
\text { Predict }\end{array}$ & $\begin{array}{c}\text { Change of Electric } \\
\text { Field } \mathbf{( k V / m )}\end{array}$ & $\begin{array}{c}\text { Temperature } \\
\left.\mathbf{(}{ }^{\circ} \mathbf{C}\right)\end{array}$ & $\begin{array}{c}\text { Humidity } \\
\mathbf{( \% )}\end{array}$ & $\begin{array}{c}\text { Accurately } \\
\text { Predict }\end{array}$ \\
\hline 1 & 52.05 & Yes & 4.19 & 6.5 & 84.8 & Yes \\
2 & 42.36 & No & 6.74 & 10.3 & 72.8 & Yes \\
3 & 58.45 & No & 4.54 & 14.4 & 68.4 & Yes \\
4 & 72.11 & Yes & 3.66 & 7.5 & 83.5 & Yes \\
5 & 66.13 & Yes & 5.63 & 7.7 & 83.2 & Yes \\
6 & 46.45 & No & 3.24 & 10.5 & 78.8 & Yes \\
7 & 58.99 & Yes & 1.09 & 7.1 & 88.9 & Yes \\
8 & 49.97 & No & 0.97 & 7.1 & 88.9 & Yes \\
9 & 64.14 & Yes & 3.22 & 12.0 & 78.9 & Yes \\
10 & 51.07 & Yes & 2.27 & 9.5 & 76.8 & Yes \\
\hline
\end{tabular}

\section{Conclusions}

In this paper, a LWS based on the electromagnetic field and the artificial neural network was developed for improving the lightning prediction accuracy. An EFM sensor was fabricated to detect the atmospheric electric field and to provide an advanced warning before lightning occurs. The loop antennas were designed to detect the magnetic field induced by lightning for estimating the direction of the lightning strike. After training the proposed neural network, the LWS was used to predict lightning incidents over six months by monitoring the change rate of electric field, temperature, and humidity. It was verified that the proposed system predicted lightning occurrence with an accuracy of $93.9 \%$, which was $27.1 \%$ higher than that of the existing LWS operated with the threshold method. The proposed system was expected to be applied in outdoor areas such as farmland, golf courses, railway systems, satellite launching centers and etc. for reducing the risk level caused by lightning strikes.

Author Contributions: Conceptualization, G.W. and G.-S.K.; Data curation, W.-H.K. and S.-W.K.; Formal analysis, G.-S.K. and S.-W.K.; Methodology, G.-S.K. and D.-W.P.; Project administration, W.-H.K.; Software, W.-H.K. and S.-W.K.; Supervision, G.-S.K.; Validation, G.W. and D.-W.P.; Writing-original draft, G.W. and S.-W.K.; Writing-review and editing, G.-S.K. and D.-W.P.

Funding: This study was supported by a grant of the SME R\&D project for the Start-up and Grow stage company, Small and Medium Business Administration, Korea (S2607792).

Conflicts of Interest: The authors declare no conflict of interest.

\section{References}

1. Haddad, A.; Warne, D.F. Advances in High Voltage Engineering, 1st ed.; The Institution of Engineering and Technology: London, UK, 2017; pp. 77-130. [CrossRef]

2. Nur, H.Z.; Mohd, Z.A.A.K.; Mohd, A.M.R.; Mahdi, I.; Norhafiz, A.; Nor, I.A.; Mohd, S.M.N. Lightning surge analysis on a large scale grid-connected solar photovoltaic system. Energies 2017, 10, 2149. [CrossRef]

3. Andreotti, A.; Mottola, F.; Pierno, A.; Proto, D. On the statistical characterization of lightning-induced voltages. Appl. Sci. 2018, 8, 651. [CrossRef]

4. David, M.R.; Jacob, T.S.; David, V.; John, M. Projected increase in lightning strikes in the United States due to global warming. Science 2014, 346, 851-854. [CrossRef]

5. Colin, P.; David, R. Possible implications of global climate change on global lightning distributions and frequencies. J. Geophys. Res. Atmos. 1994, 99, 10823-10831. [CrossRef]

6. Lightning Report; Weather Radar Center of Korea Meteorological Administration: Seoul, Korea, 2018.

7. Muhammad, A.B.S.; Hamizah, B.S.; Zainal, S.; Zokafle, B.; Zainuddin, N.; Hussein, A.; Muhammad, I.J.; Yanuar, Z.A. Lightning monitoring system for sustainable energy supply: A review. Renew. Sustain. Energy Rev. 2015, 48, 710-725. [CrossRef] 
8. Ibrahim, W.I.; Ghazali, M.R. Measurements of Electric and Magnetic Fields due to Lightning Strokes Based on Single-station Detection. In Proceedings of the IEEE Asia-Pacific Conference on Applied Electromagnetics, Melaka, Malaysia, 11 December 2012; pp. 268-273. [CrossRef]

9. Adonis, F.R.L.; Vladimir, A.R.; Jose, P.F.; Brigida, R.P.R.; Manh, D.T. A low-cost system for measuring lightning electric field waveforms, its calibration and application to remote measurements of currents. IEEE Trans. Electromagn. Compat. 2018, 60, 414-422. [CrossRef]

10. Rakov, V.A. Electromagnetic methods of lightning detection. Surv. Geophys. 2013, 34, 731-753. [CrossRef]

11. Jelena, D.; Valdas, J.; Eleonora, G.; Lukas, G.; Tahir, C.A. Effects of Weather Conditions on Electromagnetic Field Parameters. In Proceedings of the International Conference on Ecological Vehicles and Renewable Energies, Monte Carlo, Monaco, 31 March 2015; pp. 1-7. [CrossRef]

12. Salam, M.A. Influence of humidity on charge density and electric field in electrostatic precipitators. J. Phys. D Appl. Phys. 1992, 25, 1318-1322. [CrossRef]

13. Leena, H.K.; Harri, A.K.; Hiroo, T.; Jarmo, A.E. Influence of relative humidity on analyzing electric field exposure using ELF electric field measurements. Bioelectromagnetics 2013, 34, 414-418. [CrossRef]

14. Cui, Y.; Yuan, H.; Song, X.; Zhao, L.; Liu, Y.; Lin, L. Model, design, and testing of field mill sensors for measuring electric fields under high-voltage direct-current power lines. IEEE Trans. Ind. Electron. 2018, 65, 608-615. [CrossRef]

15. Martin, A.U. Lightning, 2nd ed.; Dover Publication Inc.: New York, NY, USA, 1984; pp. 47-113.

16. Vladimir, A.R.; Martin, A.U. Review and evaluation of lightning return stroke models including some aspects of their application. IEEE Trans. Electromagn. Compat. 1998, 40, 403-426. [CrossRef]

17. Kuo, P.H.; Huang, C.Y. A green energy application in energy management systems by an artificial intelligence-based solar radiation forecasting model. Energies 2018, 11, 819. [CrossRef]

18. Zhang, G.; Patuwo, B.E.; Hu, M.Y. Forecasting with artificial neural networks: The state of the art. Int. J. Forecast. 1998, 14, 35-62. [CrossRef]

19. Wang, G.M.; Kil, G.S. Measurement and analysis of partial discharge using an ultra-high frequency sensor for gas insulated structures. Metrol. Meas. Syst. 2017, 24, 515-524. [CrossRef]

(C) 2019 by the authors. Licensee MDPI, Basel, Switzerland. This article is an open access article distributed under the terms and conditions of the Creative Commons Attribution (CC BY) license (http://creativecommons.org/licenses/by/4.0/). 